\title{
Retrospective analysis of keratoconus at King Khaled Eye Specialist Hospital, Riyadh, Saudi Arabia
}

This article was published in the following Dove Press journal:

Clinical Optometry

3 April 2012

Number of times this article has been viewed

\section{Mussaed Alabdelmoneam \\ Faculty of Applied Medical Sciences, Shaqra University, Saudi Arabia}

Correspondence: Mussaed Alabdelmoneam

Department of Clinical Optometry, College of Applied Medical Sciences, Shaqra University, PO Box 33,

Shaqra I I96I, Saudi Arabia

Tel +9661 6224481

Fax +96 6I 4970785

Email malabdulmunem@su.edu.sa
Background: This work was a retrospective study undertaken in a tertiary eye care hospital to evaluate the putative prevalence and referral patterns for keratoconus by gender, age, and region of Saudi Arabia.

Methods: Files from 1638 keratoconus patients from different regions of Saudi Arabia referred to King Khaled Eye Specialist Hospital, Riyadh, Saudi Arabia, between January 1999 and December 2010 were analyzed in a retrospective manner.

Results: The patient's files were reviewed for the demographic factors of age, gender, and area of origin within Saudi Arabia. Mean age at evaluation was 21.7 (range 14-49) years. In total, 465 patients (28.39\%) were aged $21-25$ years, with 389 patients $(23.75 \%)$ being aged $16-20$ years. A minority of patients were aged 10-15 years and 46-50 years (34 [2.08\%] and 51 [3.11\%], respectively). Keratoconus patients aged 26-30 years and 31-35 years numbered $230(14.04 \%)$ and 273 (16.67\%), respectively. The distribution of patients referred with keratoconus aged 36-45 years was narrower, comprising $113(6.89 \%)$ and $83(5.07 \%)$ patients, respectively. With respect to gender, $870(53.11 \%)$ of cases were male and 768 (46.89\%) were female. With regard to region, $37.30 \%$ were referred from the central region of Saudi Arabia, $37.11 \%$ were from the southern region, $10.50 \%$ were from the northern region, and $9.34 \%$ were from the western region. The smallest number of patients came from the eastern region (5.73\%).

Conclusion: In total, 1638 patients were referred to King Khaled Eye Specialist Hospital for treatment of keratoconus from one of the five regions of Saudi Arabia at an average annual rate of referral of 136.5 patients per year. The overall distribution of keratoconus patients was almost equal between men and women, with a higher incidence in younger patients aged 16-26 years.

Keywords: keratoconus, age, gender, tertiary eye-care hospital, Saudi Arabia

\section{Introduction}

Eye diseases are a serious health problem in the Middle East, particularly in Saudi Arabia. According to the World Health Organization, there were 314 million people worldwide with visual impairment in 2002. ${ }^{1}$ The majority resided in developing countries, including Saudi Arabia. ${ }^{2}$ Visual impairment has remained a serious public health problem that has a huge and broad impact on society, with serious socioeconomic loss. ${ }^{3}$

The causes of blindness in Saudi Arabia include cataract, trachoma, nontrachomatous corneal scars, refractive errors, congenital anomalies, failed medical or surgical treatment, and glaucoma. ${ }^{4}$ Amblyopia and trauma are also important causes of less severe and often unilateral loss of vision.

There are limited numbers of studies conducted in Saudi Arabia to estimate the prevalence of visual impairment and its causes. An epidemiological study 
conducted three decades ago suggested that about $7 \%$ of all Saudi Arabians, and $42 \%$ of those older than 40 years, had cataract or its sequelae. ${ }^{5}$ Another population-based survey in the Bisha region of Saudi Arabia reported that the prevalence of blindness was $0.7 \%$ and the prevalence of visual impairment was $10.9 \%$. Cataracts were responsible for $52.6 \%$ of cases of blindness and $20.6 \%$ of cases of visual impairment. ${ }^{6}$ A recent study conducted in northern Saudi Arabia indicates that visual impairment is around $14 \%$, with the main medical causes being refractive errors $(36 \%)$, cataract $(29 \%)$, and diabetic retinopathy $(21 \%){ }^{7}$

Keratoconus is a progressive, noninflammatory corneal dystrophy characterized by corneal thinning and ectatic anterior protrusion, resulting in visual impairment. ${ }^{8-12}$ Vision loss occurs because of the corneal apex being displaced, thus creating irregular astigmatism. Corneal opacification or scarring is a result of fine breaks in Bowman's membrane and damage to Descemet's membrane in moderate to advanced keratoconus. Corneal hydrops is the painful imbibition of aqueous through breaks in Descemet's membrane, which forms a scar upon healing. ${ }^{8-12}$

The ocular symptoms and signs of keratoconus vary depending upon disease severity. In terms of histology, there are three signs which typically characterize keratoconus, ie, stromal corneal thinning with subsequent ectasia, breaks in Bowman's and Descemet's layers, and iron deposits (hemosiderin pigment) within the basal layer of the corneal epithelium at the base of the cone known as Fleischer's ring. ${ }^{8,9}$

The condition is typically bilateral, with a reported prevalence from 50 to 230 per 100,000 in the general population..$^{8,12}$ Keratoconus is reported to affect all ethnicities, with a higher prevalence in Asians than in Caucasians. ${ }^{13}$ Differences in reported prevalence rates are attributed to variations in defining keratoconus and to the diagnostic tests used in the various studies. There is a consensus that the prevalence rate for keratoconus is about 1 in 2000 worldwide. ${ }^{9}$

There are a number of studies on the incidence and prevalence of keratoconus across the world (Table 2). It is evident from the studies that keratoconus affects both genders and is reported to affect all ethnicities. A retrospective study in the Midlands of the United Kingdom reported a four-fold increase in the incidence of keratoconus in Asians compared with Caucasians. ${ }^{14}$ This increase is attributed to consanguinous relationships, particularly marriages between first cousins, implying that genetic factors contribute significantly in the etiology of keratoconus. ${ }^{13}$ Various genetic studies have implied a role of genes in the pathogenesis of keratoconus (Table 1).
Table I Identified loci in keratoconus disease

\begin{tabular}{|c|c|}
\hline Locus & References \\
\hline $5 q \mid 4.3-q 21.1$ & Tang et al ${ }^{15}$ \\
\hline $20 q-12$ & Fullerton et $\mathrm{al}^{16}$ \\
\hline $15 q 22.33-24.2$ & Hughes et $\mathrm{al}^{17}$ \\
\hline $16 q 22.3-q 23.1$ & Tyynismaa et al $^{18}$ \\
\hline $3 p \mid 4-q 13$ & Brancati et al ${ }^{19}$ \\
\hline $2 p 24$ & Hutchings et $\mathrm{a}^{20}$ \\
\hline $9 q$ & $\mathrm{Li}$ et $\mathrm{al}^{2 \mathrm{I}}$ \\
\hline $5 q 21.2$ & Bisceglia et $\mathrm{al}^{22}$ \\
\hline
\end{tabular}

A retrospective study at King Khaled Eye Specialist Hospital (KKESH), Riyadh, Kingdom of Saudi Arabia, a tertiary care ophthalmic facility, managed by the Saudi Ministry of Health, revealed that keratoconus has become the primary reason for corneal transplantation over the last 20 years. ${ }^{23}$

The World Health Organization in its 2009-2013 action plan for prevention of avoidable blindness and visual impairment asserted that population-based data on the frequency of visual impairment are urgently needed. This is crucial for identifying the need for treatment and rehabilitation services, planning, and implementing blindness prevention programs, and for determining research priorities in different populations. ${ }^{1}$

The incidence of keratoconus in the Asir province of Saudi Arabia in 2001-2002 was reported to be 20 per 100,000 population. ${ }^{24}$ There is a need to study the incidence and prevalence of keratoconus in all provinces of Saudi Arabia. KKESH is the largest ophthalmic facility in Saudi Arabia where patients from different provinces are usually referred for treatment of advanced ophthalmic conditions.

Table 2 Comparative studies of males versus females with a diagnosis of keratoconus

\begin{tabular}{|c|c|c|c|}
\hline $\begin{array}{l}\text { Males } \\
\text { with KC }\end{array}$ & $\begin{array}{l}\text { Females } \\
\text { with KC }\end{array}$ & $\begin{array}{l}\text { Patients } \\
\text { (n) }\end{array}$ & Reference \\
\hline Almost equal & Almost equal & 288 & $\mathrm{Hall}^{25}$ \\
\hline $62 \%$ & $38 \%$ & 140 & Buxton 26 \\
\hline $61 \%$ & $39 \%$ & 150 & Woodward ${ }^{27}$ \\
\hline $69.8 \%$ & $30.2 \%$ & N/A & Palimeris et $\mathrm{al}^{28}$ \\
\hline $54.7 \%$ & $45.3 \%$ & N/A & Kennedy et $\mathrm{al}^{12}$ \\
\hline 1.92 (ratio) & I (ratio) & $\mathrm{N} / \mathrm{A}$ & Tufts et $\mathrm{al}^{29}$ \\
\hline $60.1 \%$ & $39.9 \%$ & 539 & Wang et $\mathrm{al}^{30}$ \\
\hline $40.8 \%$ & $59.2 \%$ & 125 & Assiri et $\mathrm{al}^{24}$ \\
\hline $56 \%$ & $44 \%$ & 1093 & Fink et $\mathrm{al}^{31}$ \\
\hline $52.9 \%$ & $47.1 \%$ & 68 & Ljubic $^{32}$ \\
\hline $22.6 \%$ & $77.3 \%$ & 128 & Jonas et $\mathrm{al}^{33}$ \\
\hline $62 \%$ & $37.9 \%$ & 187 & Mahadevan et $\mathrm{al}^{34}$ \\
\hline $53.11 \%$ & $46.89 \%$ & 1638 & $\begin{array}{l}\text { Abdelmoneam } \\
\text { (present study) }\end{array}$ \\
\hline
\end{tabular}

Abbreviation: KC, keratoconus. 
Demographic data from KKESH may reflect the putative incidence and prevalence pattern of ophthalmic conditions in Saudi Arabia. This study attempts to estimate the prevalence of keratoconus referred to this hospital from different regions of Saudi Arabia.

\section{Material and methods}

All subjects in this retrospective study were from one of the five different geographic regions of Saudi Arabia. In total, 1638 records of patients diagnosed with keratoconus and referred to KKESH for evaluation and treatment from January 1, 1999 to December 31, 2009 were reviewed retrospectively. These records were examined for history, visual acuity, keratometry, refraction, and ocular signs. The records mentioned that corneal thickness was assessed by corneal topography and Orbscans. Diagnosis were based upon changes in best-corrected visual acuity, familial keratoconus, an irregular surface evidenced by distorted corneal curvature, keratometry, scissoring of the retinoscopic reflex, or irregularity in the red reflex on direct ophthalmoscopy. Clinical signs included at least one of the following: central corneal thinning, apical stromal scaring, Vogt's striae (thin vertical streaks in the posterior stroma or Descemet's membrane which disappear with digital pressure), Fleischer rings, or Munson's sign (protrusion of the lower lid on downgaze in patients with keratoconus). Demographic information and the national region from where the patient was referred were classified according to age, gender, and region (central, eastern, western, northern, or southern).

\section{Results}

In total, 1638 files for patients referred to KKESH from 1999 to 2009 with a diagnosis of keratoconus were reviewed. The distribution of patients with keratoconus referred to this hospital across the five regions of Saudi Arabia is shown in Figure 1. Of these patients, $870(53.11 \%)$ cases were male and $768(46.89 \%)$ cases were female. A comparison of the prevalence of keratoconus in males and females from different studies is shown in Table 2.

The distribution of patients with keratoconus referred to KKESH according to age is shown in Figure 2. The mean patient age was $21.7 \pm 7.32$ (range 14-49) years. A total of 465 patients $(28.39 \%)$ were aged $21-25$ years, followed by 389 patients $(23.75 \%)$ aged $16-20$ years. The smallest number of patients were aged 10-15 years and 46-50 years, comprising 34 (2.08\%) and 51 (3.11\%) patients, respectively. Keratoconus patients in the age range of 26-30 years and 31-35 years were 230 (14.04\%) and 273 (16.67\%), respectively. The distribution of patients referred with keratoconus aged 36-45 years narrowed down with 113 (6.89\%) and $83(5.07 \%)$ patients, respectively.

It is clear from these data that a greater number of referrals were from the central and southern regions. The data further indicate that all regions had an increasing number of referrals up to 2002, with a drop in referrals in 2003, followed by an increase through 2009, with an exception in 2008. It is unclear if this increase in referrals was due to improvements in diagnosis of keratoconus over the years or due to an increase in the incidence of keratoconus.

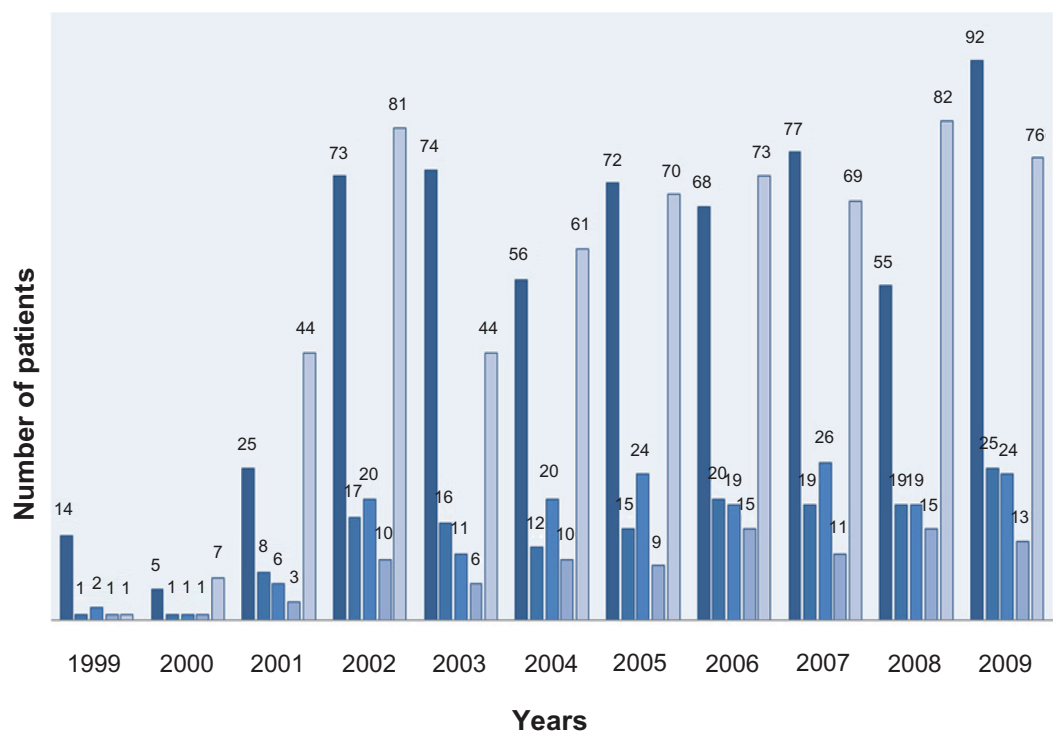

Figure I Annual distribution of keratoconus patients referred to King Khaled Eye Specialist Hospital from all regions of Saudi Arabia. 


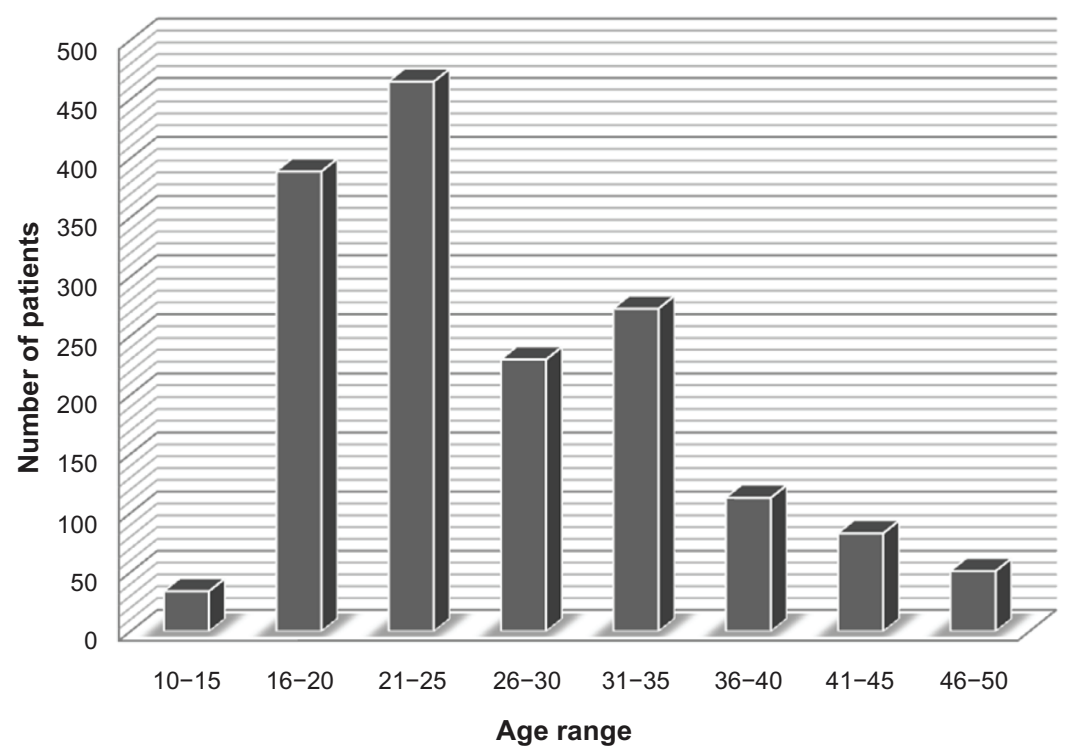

Figure 2 Age distribution of patients referred with keratoconus to King Khaled Eye Specialist Hospital from all regions of Saudi Arabia.

The central and southern regions of Saudi Arabia had a similar and higher percentage of referred cases of keratoconus, at $37.30 \%$ and $37.11 \%$, respectively. The northern and western regions had an intermediate level of referred cases at $10.50 \%$ and $9.34 \%$, respectively. The smallest percentage of referred cases $(5.73 \%)$ came from the eastern region.

Table 3 shows the total number of males and females referred with keratoconus across all five regions. In the central region, the distribution of patients referred with keratoconus amongst male (49.25\%) and female (50.25\%) patients was almost equal. For the eastern and western regions, the number of patients referred with keratoconus was greater $(61.70 \%$ and $62.10 \%$, respectively) in males than in females (38.30\% and $37.90 \%$, respectively). In the northern (54.07\% and $45.93 \%)$ and southern regions (52.63\% and $47.37 \%)$, the prevalence of referred keratoconus in males and females did not show a significant variation.

\section{Discussion}

Gender and age are important covariable factors in patients with keratoconus. Although keratoconus affects both genders, it is still unclear whether a significant difference exists between males and females. Some studies have implied that there is no significant difference in the prevalence between genders. ${ }^{8,32}$ In contrast, a few studies have found a higher prevalence in men, ${ }^{14,36}$ while one study suggests that the prevalence is higher in women. ${ }^{33}$ These gender differences can be attributed to biological differences between men and women, like hormonal changes as a result of the menstrual cycle, pregnancy, and menopause, which could cause anatomical and physiological differences between men and women. ${ }^{37}$

Table 3 Gender distribution for keratoconus patients referred to King Khaled Eye Specialist Hospital, Saudi Arabia

\begin{tabular}{|c|c|c|c|c|c|c|c|c|c|c|}
\hline \multirow[t]{2}{*}{ Year } & \multicolumn{2}{|c|}{ Central } & \multicolumn{2}{|c|}{ Eastern } & \multicolumn{2}{|c|}{ Western } & \multicolumn{2}{|c|}{ Northern } & \multicolumn{2}{|c|}{ Southern } \\
\hline & Male & Female & Male & Female & Male & Female & Male & Female & Male & Female \\
\hline 1999 & 9 & 5 & 1 & 0 & 1 & 0 & 2 & 0 & I & 0 \\
\hline 2000 & 2 & 3 & 1 & 0 & 1 & 0 & 0 & 1 & 4 & 3 \\
\hline 2001 & 10 & 15 & 2 & I & 6 & 2 & 3 & 3 & 19 & 25 \\
\hline 2002 & 37 & 36 & 4 & 6 & 10 & 7 & 11 & 9 & 49 & 32 \\
\hline 2003 & 39 & 35 & 4 & 2 & 8 & 8 & 7 & 4 & 13 & 31 \\
\hline 2004 & 27 & 29 & 7 & 3 & 10 & 2 & 7 & 13 & 28 & 33 \\
\hline 2005 & 36 & 36 & 3 & 6 & 8 & 7 & 15 & 9 & 39 & 31 \\
\hline 2006 & 32 & 36 & 9 & 6 & 12 & 8 & 8 & 11 & 37 & 36 \\
\hline 2007 & 41 & 36 & 8 & 3 & 10 & 9 & 17 & 9 & 40 & 29 \\
\hline 2008 & 29 & 26 & 9 & 6 & 13 & 6 & 11 & 8 & 44 & 38 \\
\hline 2009 & 42 & 50 & 10 & 3 & 16 & 9 & 12 & 12 & 46 & 30 \\
\hline
\end{tabular}


Our retrospective analysis suggests that there is no significant variation between the male and female patient populations, which is consistent with other reports on gender distribution. ${ }^{8,31,32,37}$

Our results showed a greater percentage (46.89\%) of female representation by $2.49 \%$, when compared with $44.4 \%$ for females in the Collaborative Longitudinal Evaluation of Keratoconus study. ${ }^{38}$ Because data acquisition was done from medical records over ten years, where it was reported that different techniques, including topography and Orbscan, were used in patients for the screening and diagnosis of keratoconus. It is quite possible that the results obtained over ten years could incorporate bias because of use of different kinds of techniques being employed in diagnosis.

Furthermore, according to this study, the prevalence of keratoconus was higher in younger patients aged 16-26 years when compared with older patients aged $36-50$ years. This is consistent with previous studies, in which it was proposed that progression of keratoconus slows down with age.

The ability to describe the prevalence of a disease is important for predicting current and future clinical needs, and for establishing disease characteristics in a particular population. It is not common practice to obtain epidemiological data from registrations at a tertiary care center.

$\mathrm{KKESH}$ is the largest tertiary care ophthalmic facility in the Kingdom of Saudi Arabia, and is involved in conducting epidemiological studies that have provided useful data for planning allocation of eye care resources in Saudi Arabia. ${ }^{35}$ The present study is the first attempt to investigate the prevalence of keratoconus in the general Saudi population. This study allowed us to undertake a detailed prospective study on keratoconus, which could address all the shortcomings of our retrospective study in order to consolidate our observation in a comprehensive way.

In this study, the estimated prevalence of keratoconus referred to KKESH in Saudi Arabia is 0.81 per 100,000 citizens, which is lower than what has been previously reported. This lower prevalence of keratoconus observed at KKESH may be a result of some patients being referred to other ophthalmic facilities or hospitals, in or out of Saudi Arabia, suggesting that the results of this study may not be a true representation of prevalence of keratoconus in Saudi Arabia. A potential for underdiagnosis and undertreatment exists. Improved screening and diagnostic strategies could identify currently unrecognized keratoconus cases. There is also a need for studies evaluating the contribution of environmental or geographical factors to the prevalence and severity of keratoconus. An earlier report suggested that the prevalence is related to a combination of both genetic and environmental factors. This study of keratoconus patients at KKESH confirms the putative prevalence of keratoconus, which does not appear to vary significantly amongst the different regions within the Saudi Arabia. It can be inferred from the widespread frequency of consanguinous marriages in Saudi Arabia that the prevalence of keratoconus should be significantly higher, particularly if there is a factor of autosomal recessive inheritance. ${ }^{10}$

\section{Disclosure}

The author reports no conflict of interest in this work.

\section{References}

1. World Health Organization. Action Plan for the Prevention of Avoidable Blindness and Visual Impairment, 2009-2013. Geneva, Switzerland: World Health Organization; 2009.

2. Poskitt EME, Cole TJ, Lawson DEM. Diet, sunlight and 25-hydroxyvitamin D in healthy children and adults. Br Med J. 1979;1: 221-223.

3. Lawson DEM, Paul A, Cole TJ, Mandal AR, Davie M. Relative contribution of diet and sunlight to vitamin D state in the elderly. $\mathrm{Br}$ Med J. 1979;2:303-305.

4. Tabbara KF. Blindness in the eastern Mediterranean countries. $\mathrm{Br} J$ Ophthalmol. 2001;85:771-775.

5. Tabbara KF, Ross-Degnan D. Blindness in Saudi Arabia. JAMA 1986;255:3378-3384.

6. Al Faran MF, Rajhi AA, Omar OM, Ghamdi SA, Jabak M. Prevalence and causes of visual impairment and blindness in the south western region of Saudi Arabia. Int Ophthalmol. 1993;17:161-165.

7. Al-Shaaln FF, Bakrman MA, Ibrahim AM, Aljoudi AS. Prevalence and causes of visual impairment among Saudi adults attending primary health care centers in northern Saudi Arabia. Ann Saudi Med. 2011;31:473-480.

8. Krachmer JH, Feder RS, Belin MW. Keratoconus and related noninflammatory corneal thinning disorders. Surv Ophthalmol. 1984;28: 293-322.

9. Rabinowitz YS. Keratoconus. Surv Ophthalmol. 1998;42:297-319.

10. Saini JS, Saroha V, Singh P, Sukhija JS, Jain AK. Keratoconus in Asian eyes at a tertiary eye care facility. Clin Exp Optom. 2004;87:97-101.

11. Falavarjani KG, Modarres M, Joshaghani M, Azadi P, Afshar AE, Hodjat P. Interocular differences of the Pentacam measurements in normal subjects. Clin Exp Optom. 2010;93:26-30.

12. Kennedy RH, Bourne WM, Dyer JA. A 48-year clinical and epidemiologic study of keratoconus. Am J Ophthalmol. 1986;101:267-273.

13. Georgiou T, Funnell CL, Cassels-Brown A, O'Conor R. Influence of ethnic origin on the incidence of keratoconus and associated atopic disease in Asians and white patients. Eye (Lond). 2004;18:379-383.

14. Pearson AR, Soneji B, Sarvananthan N, Sandford-Smith JH. Does ethnic origin influence the incidence or severity of keratoconus? Eye (Lond). 2000; $14: 625-628$.

15. Tang YG, Rabinowitz YS, Taylor KD, et al. Genomewide linkage scan in a multigeneration Caucasian pedigree identifies a novel locus for keratoconus on chromosome 5q14.3-q21.1. Genet Med. 2005;7:397-405.

16. Fullerton J, Paprocki P, Foote S, Mackey D, Williamson R, Forrest S. Identity-by-descent approach to gene localisation in eight individuals affected by keratoconus from north-west Tasmania, Australia. Hum Genet. 2002;110:462-470.

17. Hughes AE, Dash DP, Jackson AJ, Frazer DG, Silvestri G. Familial keratoconus with cataract: linkage to the long arm of chromosome 15 and exclusion of candidate genes. Invest Ophthalmol Vis Sci. 2003;44:5063-5066 
18. Tyynismaa $\mathrm{H}$, Sistonen $\mathrm{P}$, Tuupanen $\mathrm{S}$, et al. A locus for autosomal dominant keratoconus: linkage to 16q22.3-q23.1 in Finnish families. Invest Ophthalmol Vis Sci. 2002;43:3160-3164.

19. Brancati F, Valente EM, Sarkozy A, et al. A locus for autosomal dominant keratoconus maps to human chromosome 3p14-q13. J Med Genet. 2004;41:188-192.

20. Hutchings H, Ginisty H, Le Gallo M, et al. Identification of a new locus for isolated familial keratoconus at 2p24. J Med Genet. 2005;42:88-94.

21. Li X, Rabinowitz YS, Tang YG, et al. Two-stage genome-wide linkage scan in keratoconus sib pair families. Invest Ophthalmol Vis Sci. 2006;47:3791-3795.

22. Bisceglia L, De Bonis P, Pizzicoli C, et al. Linkage analysis in keratoconus: replication of locus 5q21.2 and identification of other suggestive loci. Invest Ophthalmol Vis Sci. 2009;50:1081-1086.

23. Al-Towerki A-E, Gonnah E-S, Al-Rajhi A, Wagoner MD. Changing indications for corneal transplantation at the King Khaled Eye Specialist Hospital (1983-2002). Cornea. 2004;23:584-588.

24. Assiri AA, Yousuf BI, Quantock AJ, Murphy PJ. Incidence and severity of keratoconus in Asir province, Saudi Arabia. Br J Ophthalmol. 2005; 89:1403-1406.

25. Hall KG. A comprehensive study of keratoconus. Br J Physiol Opt. $1963 ; 20: 215-256$

26. Buxton JN. Keratoconus. In: Symposium on contact lenses. Transactions of the New Orleans Academy of Ophthalmology. St Louis, MO: CV Mosby; 1973.

27. Woodward EG. Keratoconus - epidemiology. Cont Lens Anterior Eye. 1984; 7:64-76

28. Palimeris G, Droutsas D, Chimonidou E, Moschou M. Some observations on the pathogenesis and management of keratoconus. In: Trevor-Roper T, editor. VIth Congress of the European Society of Ophthalmology. London, UK: The Royal Society of Medicine and Academic Press; 1981.
29. Tuft SJ, Moodaley LC, Gregory WM, Davison CR, Buckley RJ. Prognostic factors for the progression of keratoconus. Ophthalmology. 1994;101:439-447.

30. Wang Y, Rabinowitz YS, Rotter JI, Yang H. Genetic epidemiological study of keratoconus: Evidence for major gene determination. Am J Med Genet. 2000;93:403-409.

31. Fink BA, Wagner H, Steger-May K, et al. Differences in keratoconus as a function of gender. Am J Ophthalmol. 2005;140:459-468.

32. Ljubic AD. Keratoconus and its prevalence in Macedonia. Macedonian Journal of Medical Sciences. 2009;2:58-62.

33. Jonas JB, Nangia V, Matin A, Kulkarni M, Bhojwani K. Prevalence and associations of keratoconus in rural Maharashtra in Central India: The Central India Eye and Medical Study. Am J Ophthalmol. 2009;148:760-765.

34. Mahadevan R, Arumugam AO, Arunachalam V, Kumaresan B. Keratoconus - a review from a tertiary eye-care center. J Optom. 2009;2:166-172.

35. King Khaled Eye Specialist Hospital. Research department overview [web page on the Internet]. Available from: http://www.kkesh.med.sa/ kkeshweb/en/Section.aspx?SectionID=35\&TopicID=64\&TopicName =Overview. Accessed November 5, 2011.

36. Owens H, Gamble G. A profile of keratoconus in New Zealand. Cornea. $2003 ; 22: 122-125$

37. Ertan A, Muftuoglu O. Keratoconus clinical findings according to different age and gender groups. Cornea. 2008;27:1109-1113.

38. Davis LJ, Schechtman KB, Wilson BS, et al; The Collaborative Longitudinal Evaluation of Keratoconus Study Group. Longitudinal changes in visual acuity in keratoconus. Invest Ophthalmol Vis Sci. 2006;47:489-500.
Clinical Optometry

\section{Publish your work in this journal}

Clinical Optometry is an international, peer-reviewed, open access journal publishing original research, basic science, clinical and epidemiological studies, reviews and evaluations on clinical optometry. All aspects of patient care are addressed within the journal as well as the practice of optometry including economic and business analyses. Basic and clinical

\section{Dovepress}

research papers are published that cover all aspects of optics, refraction and its application to the theory and practice of optometry. The manuscript management system is completely online and includes a very quick and fair peer-review system, which is all easy to use. Visit http://www.dovepress. com/testimonials.php to read real quotes from published authors. 